\title{
Serum ANGPTL4 and FGF2, energy-related blood biochemicals, cytokine responses and oxidative stress in dairy cows with subclinical ketosis
}

\author{
Efe KURTDEDE ${ }^{1, a, \bowtie}$, Arif KURTDEDE ${ }^{2, b}$, Naci ÖCAL $^{3, c}$, Erdal KARA ${ }^{3, d}$ \\ ${ }^{1}$ Ankara University, Veterinary Faculty, Biochemistry Department, Ankara, Türkiye; ${ }^{2}$ Ankara University, Veterinary Faculty, Internal Medicine \\ Department, Ankara, Türkiye; ${ }^{3}$ Kırıkkale University, Veterinary Faculty, Internal Medicine Department, Kırıkkale, Türkiye
}

aORCID: 0000-0001-8436-3332; bORCID: 0000-0003-0537-7256; ' ORCID: 0000-0002-8679-2111; dORCID: 0000-0001-7047-9502

\begin{tabular}{|c|c|}
\hline ARTICLE INFO & A B STRACT \\
\hline Article History & In this study, it was aimed to investigate the serum levels of ANGPTL4, FGF21, \\
\hline Received : 31.03 .2021 & IL-1 $1 \beta, I L-6, S O D, M D A$, and serum biochemical and hematological parameters \\
\hline Accepted: 04.11 .2021 & in cows with subclinical ketosis. The mean serum $\beta$-hydroxybutyric acid (BHB) \\
\hline DOI: $10.33988 /$ auvfd. 907076 & level was $1.37 \pm 0.04 \mathrm{mmol} / \mathrm{L}$ in 10 dairy cows aged $3-5$ years that were $<21$ \\
\hline & days postpartum and diagnosed with subclinical ketosis. The mean serum BHB \\
\hline Keywords & level was $0.40 \pm 0.08 \mathrm{mmol} / \mathrm{L}$ in 10 healthy dairy cows in the same period and \\
\hline Cytokines & in the same age range. An increase in serum AST $(P<0.001)$ and a decrease in \\
\hline Energy-related biochemical & serum albumin levels $(P<0.05)$ indicated altered liver functions. An increase in \\
\hline Hepatokines & serum non-esterified fatty acid $(P<0.001)$ and decreases in serum $H D L$, \\
\hline Subclinical ketosis & $\begin{array}{l}\text { triglyceride, and total cholesterol levels }(P<0.05) \text { were interpreted as } \\
\text { indicators of increased metabolic pathology risk due to negative energy }\end{array}$ \\
\hline${ }^{\otimes}$ Corresponding author & balance. Increases in serum ANGPTL4, FGF2, IL-1B, IL-6, and MDA $(P<0.001)$ \\
\hline efekurtdede@gmail.com & and SOD levels $(P<0.05)$ were evaluated as indicators of the development of \\
\hline $\begin{array}{l}\text { How to cite this article: Kurtdede E, Kurtdede A, } \\
\text { Öcal N, Kara E (2023): Serum ANGPTL4 and FGF2, } \\
\text { energy-related blood biochemicals, cytokine } \\
\text { responses and oxidative stress in dairy cows with } \\
\text { subclinical ketosis. Ankara Univ Vet Fak Derg, } 70 \\
\text { (1), 37-42. DOI: } 10.33988 / \text { auvfd.907076. }\end{array}$ & $\begin{array}{l}\text { significant increases in serum ANGPTL4, FGF2, IL-1 } \beta, I L-6 \text {, and MDA and SOD } \\
\text { levels in dairy cows with subclinical ketosis were associated with negative } \\
\text { energy balance, effective cytokine responses, and oxidative stress. }\end{array}$ \\
\hline
\end{tabular}

\section{Introduction}

In cows with high milk production, increased energy requirement and inadequate food intake result in negative energy balance (NEB) and subclinical ketosis at 7-28 days postpartum $(6,7)$.

Subclinical ketosis is characterized by a decrease in blood glucose and depletion of liver glycogen and other glucose reserves and gluconeogenesis activity, and lipid degradation in the liver, and an increase in ketone bodies in the blood $(24,38)$.

In NEB cows, changes in body lipid reserves result in increased circulating body levels of non-esterified fatty acids (NEFAs) and ketones. This adversely affects all tissues, but especially the liver $(7,12,32)$.
Serum HDL, triglyceride, and total cholesterol are the main indicators of postpartum lipid metabolism changes $(12,23)$.

Angiopoietin-like 4 (ANGPTL4) is a glycoprotein that stimulates lipolysis by inhibiting lipoprotein lipase (LPL) activity, and thus regulates systemic energy and lipid metabolism. Fibroblast growth factor 21 (FGF21) is a hormonal factor that takes part in the regulation of metabolic response, such as hepatic lipid oxidation and ketogenesis, during energy deprivation (28). In dairy cows, circulating FGF21 and ANGPTL4 are predominantly expressed in the liver and adipose tissue metabolism due to negative energy balance $(3,20,29)$.

It is important to determine serum total protein, albumin, glucose, and aspartate amino transaminase 
(AST) levels in dairy cows in NEB $(22,25)$. Previous researchers $(15,18)$ indicate the utility of blood urea and creatinine levels and urine creatinine/total protein ratio in the assessment of renal functions in cows with subclinical ketosis.

Halliwell (13) reported that increased cellular respiration by-products in mitochondria during the postpartum period caused a marked increase in blood free radical levels, which is an indicator of oxidative stress. Oxidative stress, which increases due to lipid mobilization and activation of phagocytic cells and cytokines, is a part of the complex metabolic response process in cows in $\operatorname{NEB}(5,35)$. One parameter used in determining oxidative stress is SOD, which is involved in the natural elimination of O2-. Another parameter is MDA, which is a by-product of lipid peroxidation, and is used to evaluate the oxidative degradation of lipids (1).

In high milk yielding cows, hematological values can prove useful in determining the metabolic status and the presence, severity, and prognosis of clinical and subclinical diseases $(11,21)$. Lacetera et al. (17) reported a possible relationship between the lymphocyte count and serum BHB and NEFA levels.

During the development of postnatal NEB, proinflammatory cytokines such as IL-1 and IL-6 actively participate in increases in serum NEFA and BHB, along with the acceleration of metabolic activation. IL-6 is involved in the development of metabolic inflammation and immunological response in cows with subclinical ketosis. In addition, IL-6 plays an important role in lipoprotein metabolism, fatty acid oxidation, urea cycle, oxidative stress, and proteasome activation $(19,37)$.

In the present study, we aimed to investigate the serum levels of ANGPTL4, FGF21, IL-1 $\beta$, IL-6, SOD, MDA, and serum biochemical and hematological parameters in cows with subclinical ketosis.

\section{Materials and Methods}

Sampling: Twenty dairy cows on the same dairy farm, $<21$ days postpartum, 3-5 years old, and having given birth to two or more calves were included in the study. Calving took place in the autumn-winter sessions. Cows with a BCS of 3.5 were selected from cows with a BCS $<0.5$ from the dry period to calving. Animals with a previous lactation period and a longer drying period and with a previous history of metabolic disease were excluded from the study. Blood samples were taken approximately 4 hours after feeding.

The subclinical ketosis group consisted of 10 dairy cows with atypical symptoms of subclinical ketosis (lethargy, weight loss, decreased appetite, decreased milk production, and change in milk consistency). In this group mean blood serum BHB (mean $1.37 \pm 0.04 \mathrm{mmol} / \mathrm{L}$ ) was $>1.20$ and ketone bodies were absent in their urine samples. The control group included 10 healthy dairy cows that did not have clinical symptoms of any diseases and whose blood serum BHB (mean $0.40 \pm 0.08 \mathrm{mmol} / \mathrm{L}$ ) was $<1.20$.

Urinalysis: Samples were collected from urine during manual perineal massage. Urine samples were analyzed for ketone bodies within 1 hour with strip method, and the remainder aliquoted into $5 \times 1.5 \mathrm{~mL}$ plastic tubes and stored at $-80^{\circ} \mathrm{C}$ until creatinine/protein ratio measurement.

Blood analysis: A total of $7 \mathrm{~mL}$ of blood was collected from the tail vein of cows; $5 \mathrm{~mL}$ was placed into coagulation tubes for serum samples and $2 \mathrm{~mL}$ into tubes containing anticoagulant (EDTA). Serum samples separated from blood samples immediately after collection were placed in Dappen dishes and stored at $-80{ }^{\circ} \mathrm{C}$.

Hematological parameters were studied in EDTA blood samples using a Mindray BC-5000 device.

In serum and urine samples thawed at room temperature before test applications, serum albumin, glucose, urea, uric acid, creatinine, total protein, aspartate amino transaminase (AST), and total bilirubin were measured using an automated biochemistry analyzer (Mindray BS-120). Quantitative analysis of protein and creatinine in urine samples was performed using a Mindray BS-300 device.

A portable measuring device (VET-TD-4235 Beta Keton Monitoring System, TalDoc Technology Corporation, Taiwan, ROC) was used to determine the level of BHB.

ANGPTL4, FGF21, and serum NEFA, IL-1 $\beta$, and IL-6 levels were measured using respective ELISA test kits (Sun Red Biotechnology Company, Cat No: 201-04291, Cat No: 201-04-3155, Cat No: 201-04-0186, Cat No: 201-04-0157, and Cat No: 201-04-0008). Serum superoxide dismutase (SOD) level was measured using a Cayman 706002 commercial test kit. Serum malondialdehyde (MDA) level was measured using a commercial ELISA test kit (Sun Red Biotechnology Company, Cat No: 2.01-04-0255).

Statistical analysis: For statistical assessment, prior to testing for statistical significance, all data were tested for parametric test assumptions, namely normality with the Shapiro-Wilk test and homogeneity with Levene's test. The differences between the two groups were analyzed using Student's t-test when parametric assumptions were met and the Mann-Whitney $U$ test otherwise. All statistical analyses were examined with a 5\% margin of error. The data were analyzed using SPSS v.14.01.

\section{Results}

Mean serum BHB level was $1.37 \pm 0.04 \mathrm{mmol} / \mathrm{L}$ in the cows diagnosed with subclinical ketosis and $0.40 \pm 0.08$ $\mathrm{mmol} / \mathrm{L}$ in the control group. The significantly elevated BHB levels $(\mathrm{P}<0.001)$ in the cows with subclinical ketosis were ascribed to developing NEB. 
The glucose, albumin, total protein, AST, total cholesterol, triglycerides, HDL, and AST levels of the cows with subclinical ketosis and the controls are presented in Table 1. In the cows with subclinical ketosis, increase in serum AST $(\mathrm{P}<0.001)$, decrease in serum albumin $(\mathrm{P}<0.05)$, and decrease in serum HDL, triglyceride, and total cholesterol $(\mathrm{P}<0.05)$ were determined compared to the values in the control group.

The NEFA, BHB, ANGPTL4, FGF21, IL-1 $\beta$, and IL-6 levels of the cows with subclinical ketosis and the controls are presented in Table 2. Significantly increases were found in serum BHB, NEFA, ANGPTL4, FGF21, IL-1 $\beta$, and IL- 6 values in the dairy cows with subclinical ketosis compared to the values determined in the healthy cows $(\mathrm{P}<0.001)$.
The urea, creatinine, urine protein/creatinine, SOD, and MDA levels of the cows with subclinical ketosis and the controls are presented in Table 3. The urea and SOD levels of the subclinical ketosis and control groups were significantly different $(\mathrm{P}<0.05)$. Statistically significant changes were determined in serum urea, SOD, and MDA values in the cows with subclinical ketosis compared to the values determined in the control cows. There was no statistical difference in serum creatinine and urine protein/creatinine values $(\mathrm{P}<0.001)$.

The WBC, lymphocyte, monocyte, neutrophil, and eosinophil counts of the cows with subclinical ketosis and the controls are presented in Table 4. No statistically significant difference was found in blood parameters.

Table 1. Glucose, albumin, total protein, AST, total cholesterol, triglycerides, HDL, and levels of the cows with subclinical ketosis and the controls.

\begin{tabular}{lccccccc}
\hline Groups & Glucose & Albumin & Total & $\begin{array}{c}\text { Biochemical Parameters } \\
\text { Total } \\
(\mathbf{m g} / \mathbf{d L})\end{array}$ & $\begin{array}{c}\text { Triglyceride } \\
\text { Cholesterol } \\
(\mathbf{m g} / \mathbf{d L})\end{array}$ & $\begin{array}{c}\text { HDL } \\
(\mathbf{m g} / \mathbf{d L})\end{array}$ & $\begin{array}{c}\text { AST } \\
(\mathbf{U} / \mathbf{L})\end{array}$ \\
\hline Control & $55.5 \pm 11.81$ & $2.96 \pm 0.66$ & $6.95 \pm 1.72$ & $159.6 \pm 3.82$ & $8.3 \pm 3.16$ & $155.2 \pm 10.35$ & $57.2 \pm 10.45$ \\
Subclinical Ketosis & $49.4 \pm 12.24$ & $2.35 \pm 0.61 *$ & $5.90 \pm 1.92$ & $122.6 \pm 34.21^{*}$ & $6.0 \pm 2.62 *$ & $103.8 \pm 21.65^{* *}$ & $78.2 \pm 10.32^{* *}$ \\
\hline
\end{tabular}

The results are presented as arithmetic mean \pm standard deviation.

*The AST and HDL levels $(\mathrm{P}<0.001)$.

**The albumin, total cholesterol, and triglyceride measurements $(\mathrm{P}<0.05)$ of the two groups were significantly different (albumin $\mathrm{P}=0.044$, total cholesterol $\mathrm{P}=0.025$, triglyceride $\mathrm{P}=0.094)$.

Table 2. The NEFA, BHB, ANGPTL4, FGF21, IL-1 $\beta$, and IL-6 levels of the cows with subclinical ketosis and the controls.

\begin{tabular}{lcccccc}
\hline Groups & $\begin{array}{c}\text { BEFA } \\
(\boldsymbol{\mu m o l} / \mathbf{m L})\end{array}$ & $\begin{array}{c}\text { ANGPTL4 } \\
(\mathbf{n g} / \mathbf{m L})\end{array}$ & $\begin{array}{c}\text { FGF 21 } \\
(\mathbf{n g} / \mathbf{L})\end{array}$ & $\begin{array}{c}\text { IL-1 } \boldsymbol{\beta} \\
(\mathbf{n g} / \mathbf{m L})\end{array}$ & $\begin{array}{c}\text { IL-6 } \\
(\mathbf{n g} / \mathbf{m L})\end{array}$ & $\begin{array}{c}\text { BHB } \\
(\mathbf{m m o l} / \mathbf{L})\end{array}$ \\
\hline Control & $0.33 \pm 0.07$ & $5.81 \pm 1.12$ & $509.68 \pm 26.36$ & $113.20 \pm 13.87$ & $4.97 \pm 0.45$ & $0.40 \pm 0.08$ \\
Subclinical Ketosis & $0.70 \pm 0.05^{*}$ & $15.16 \pm 2.5^{*}$ & $1323.58 \pm 70.82^{*}$ & $148.85 \pm 17.22^{*}$ & $13.38 \pm 1.37 *$ & $1.37 \pm 0.04 *$ \\
\hline
\end{tabular}

The results are presented as arithmetic mean \pm standard deviation.

* The NEFA, ANGPTL4, FGF 21, IL-1 $\beta$, IL-6, and BHB levels of the two groups were significantly different $(\mathrm{P}<0.001)$.

Table 3. Urea, creatinine, urine protein/creatinine, SOD, and MDA levels of the cows with subclinical ketosis and the controls.

\begin{tabular}{|c|c|c|c|c|c|}
\hline \multirow{2}{*}{ Groups } & \multicolumn{5}{|c|}{ Biochemical Parameters } \\
\hline & $\begin{array}{c}\text { Urea } \\
(\mathbf{m g} / \mathbf{d L})\end{array}$ & $\begin{array}{c}\text { Creatinine } \\
(\mathrm{mg} / \mathrm{L})\end{array}$ & $\begin{array}{c}\text { Urine protein / } \\
\text { creatinine }\end{array}$ & SOD U/g protein & $\begin{array}{c}\text { MDA nmol/g } \\
\text { protein }\end{array}$ \\
\hline Control & $15.93 \pm 3.69$ & $0.96 \pm 0.26$ & $0.08 \pm 0.02$ & $67.60 \pm 8.43$ & $3.75 \pm 0.23$ \\
\hline Subclinical Ketosis & $18.94 \pm 4.4 *$ & $1.22 \pm 0.13$ & $0.07 \pm 0.02$ & $80.14 \pm 6.59^{*}$ & $4.68 \pm 0.19 * *$ \\
\hline
\end{tabular}

The results are presented as arithmetic mean \pm standard deviation.

* The urea and SOD levels of the subclinical ketosis and control groups were significantly different $(\mathrm{P}<0.05)($ urea $\mathrm{P}=0.033, \mathrm{SOD} \mathrm{P}=0.002)$.

** The MDA levels of the subclinical ketosis and control groups were significantly different $(\mathrm{P}<0.001)$.

Table 4. WBC, lymphocyte, monocyte, neutrophil, and eosinophil counts of the cows with subclinical ketosis and the controls.

\begin{tabular}{lccccc}
\hline Groups & \multicolumn{4}{c}{ Hematological Parameters } \\
& $\begin{array}{c}\text { WBC } \\
(\mathbf{1 0} / \mathbf{L})\end{array}$ & $\begin{array}{c}\text { Lymphocyte } \\
\left(\mathbf{1 0}^{9} / \mathbf{L}\right)\end{array}$ & $\begin{array}{c}\text { Monocyte } \\
\left(\mathbf{1 0}^{9} / \mathbf{L}\right)\end{array}$ & $\begin{array}{c}\text { Neutrophil } \\
(\mathbf{1 0} / \mathbf{L})\end{array}$ & $\begin{array}{c}\text { Eosinophil } \\
(\mathbf{1 0} / \mathbf{L})\end{array}$ \\
\hline Control $(\mathrm{n}=10)$ & $8.83 \pm 4.16$ & $5.35 \pm 2.48$ & $0.24 \pm 0.16$ & $2.88 \pm 2.81$ & $0.30 \pm 0.14$ \\
Subclinical ketosis $(\mathrm{n}=10)$ & $9.84 \pm 1.67$ & $6.53 \pm 2.48$ & $0.30 \pm 0.27$ & $2.56 \pm 1.03$ & $0.33 \pm 0.17$ \\
\hline No statistically significant difference was found in blood parameters. But there is a numerical increase in the lymphocyte count in the cows with
\end{tabular}

No statistically significant difference was found in blood parameters. But there is a numerical increase in the lymphocyte count in the cows with subclinical ketosis, although it was not statistically significant. 


\section{Discussion and Conclusion}

The development and progression of NEB in dairy cows during the first 21 days postpartum and the subsequent mobilization of fat to the liver for utilization elevate serum BHB and NEFA levels, the most important laboratory indicators of subclinical ketosis (10). In the present study, subclinical ketosis was diagnosed in dairy cows at $<21$ days postpartum through significantly elevated serum BHB as well as serum NEFA levels and the absence of ketone bodies in the urine. In defining subclinical ketosis, Folnozic et al. (10) ann Basbug et al. (4) considered both serum BHB and NEFA levels was found decisive,

In cows with subclinical ketosis, when the serum BHB value rises above $1.2 \mathrm{mmol} / \mathrm{L}$, serum ANGPTL4 and FGF21 values also start to increase, indicating a response of lipid metabolism. If this metabolic response is prolonged, laboratory and clinical findings associated with subclinical ketosis become more prominent (9). Findings including clear clinical signs of ketosis and the presence of ketone bodies in urine suggest that ketosis has developed in cows (14). We thought that the cows in the present study were in the early stages of subclinical ketosis development, since the mean serum BHB level (1.37 \pm $0.04 \mathrm{mmol} / \mathrm{L}$ ) measured in 10 cows with subclinical ketosis was slightly above the threshold value (1.2 $\mathrm{mmol} / \mathrm{L}$ ). Issi et al. (15) stated that serum total protein, albumin, glucose, and aspartate amino transaminase levels provide important information about the functional status of the liver in cows with subclinical ketosis. In the present study, low total protein, albumin, and glucose levels and high aspartate amino transaminase levels measured in 10 cows with subclinical ketosis were attributed to liver degradation, which was thought to be caused by changes in lipid metabolism. Chen et al. (8) reported low serum glucose, triglyceride, and creatinine levels and elevated serum NEFA and AST levels in cows with subclinical ketosis with BHB levels of 1.2-1.6 mmol/L.

Many studies have shown that serum NEFA levels increase and HDL, triglyceride, and total cholesterol levels decrease as a result of NEB and lipid mobilization in the postpartum period $(4,10,15,27)$. In our study, a statistically significant increase in serum NEFA level in cows with subclinical ketosis showed that significant lipid mobilization had developed in the patients. In addition, statistically significant decreases in serum albumin, total protein, HDL, triglyceride, and total cholesterol levels indicated that the liver was mildly/moderately affected by the increased activity in lipid metabolism.

Similar to our results, Marutsova et al. (22) reported reduced serum total protein and albumin levels in dairy cows with subclinical ketosis, whereas Antanaitis et al. (2) reported increased total protein level and reduced albumin level and Issi et al. (15) demonstrated that total protein had increased.
Some researchers $(15,18)$ have suggested that serum urea, creatinine, and urine creatinine/total protein ratios are important indicators for evaluating renal functions in subclinical ketosis. In the present study, statistically significant changes were determined in serum urea, SOD, and MDA values in the cows with subclinical ketosis compared to the values determined in the control cows. However, there was no significant difference in serum creatinine or urine protein/creatinine values. The increase in serum urea level was found to be consistent with the findings reported by Issi et al. (15). Issi et al. (15) highlighted that serum urea and creatinine levels are increased in cows with subclinical ketosis and argue that glomerular filtration rate should be investigated to assess kidney functions. We recommend further studies that investigate renal functions using more sensitive and invasive methods.

Consistent with the findings published by Senoh et al. (31) and Karimi et al. (16), in the present study significant increases in serum MDA $(\mathrm{P}<0.001)$ and SOD $(\mathrm{P}<0.05)$ values and changes in energy-related metabolic parameters in cows with subclinical ketosis suggested that the cause of oxidative stress occurring in animals with subclinical ketosis was "ketosis-related acceleration in lipid mobilization". Some researchers $(5,26,35)$ claimed that oxidative stress in postnatal dairy cows developed as a result of lipid mobilization in cows in NEB.

Zhang et al. (39) stated that an increase in serum NEFA level in the postpartum period in cows with NEB causes excessive production of polymorphic cells and proinflammatory cytokines, and, therefore, systemic inflammation and neutrophil counts may increase in cows with ketosis. The lack of statistically significant changes in hematological parameters in cows with NEB in our study may have been related to the severity of the disease and the length of the disease process, or it may have been due to the fact that serum NEFA values were not sufficiently elevated to affect hematological parameters. Schulz et al. (30) and Marutsova et al. (21) pointed out that the lymphocyte count is high in cows in the postnatal period in NEB. Similarly, in the present study, a numerical increase in lymphocyte count was noted in cows with subclinical ketosis, although it was not statistically significant.

Serum levels of ANGPTL4 and FGF21, which are synthesized by the liver and adipose tissue, are important in evaluating the stimulation of lipolysis, inhibition of lipogenesis and hepatic lipid oxidation, fatty acid oxidation, and the stimulation of ketogenesis in the liver (8). Wang et al. (36) reported increased serum NEFA, ANGPTL4, and FGF21 levels in postpartum cows with ketosis and fatty liver. Chen et al. (8) reported that serum FGF21 is a significant biomarker in cows with subclinical ketosis, which FGF21 continues to increase until serum BHB reaches $1.6 \mathrm{mmol} / \mathrm{L}$, and that FGF21 starts to 
decrease after BHB exceeds $1.6 \mathrm{mmol} / \mathrm{L}$. In the present study, serum BHB, ANGPTL4, and FGF21 levels were elevated in cows with subclinical ketosis $(\mathrm{P}<0.001)$. A concomitant significant increase in serum NEFA levels supports the stimulation of lipolysis, inhibition of lipogenesis, hepatic lipid oxidation, fatty acid oxidation, and the stimulation of ketogenesis in the liver.

According to Trevisi et al. (33), high prenatal serum IL-1 $\beta$ and IL-6 levels were associated with increased oxidative stress parameters and this effect decreased, but postpartum 7-21. They stated that it continued. Trevisi et al. (34) recently reported a positive correlation between decreased liver function due to inflammation, metabolic stress, and increased serum IL-6 levels in lactating cows. Similarly, significant increases in serum BHB, NEFA, ANGPTL4, FGF21, IL-1 $\beta$, IL-6, SOD, and MDA levels in dairy cows with subclinical ketosis showed effective metabolic, inflammatory, and oxidative stress in our study.

As a result of the present study, it is thought that there is no renal dysfunction that will significantly change serum creatinine and urinary creatinine/protein levels in cows with subclinical ketosis, and the level of kidney function loss can be evaluated with more sensitive methods. The increase in serum AST level and decrease in serum albumin level showed some deterioration in liver functions in these patients. In response to the NEB that developed in the patients, serum NEFA levels increased, while serum HDL, triglyceride, and total cholesterol levels decreased. Significant increases in serum SOD and MDA levels showed that patients developed significant oxidative stress. Elevated serum ANGPTL4 and FGF21 levels in the patient indicated that the liver and adipose tissue still had the ability to respond to negative energy-induced metabolic stress in cows with subclinical ketosis in NEB.

In conclusion, significant increases in serum IL-1 $\beta$, IL-6, SOD, and MDA levels in dairy cows with subclinical ketosis were evaluated as indicators of effective metabolic, inflammatory, and oxidative stress development. The increase in oxidative stress markers along with the increase in FGF21 level was considered a remarkable finding. Considering that serum FGF21 has the function of supporting lipid oxidation and ketogenesis as an energy source in a low glucose environment, it was evaluated that significant increases in serum ANGPTL4 and FGF2 levels were associated with NEB, cytokine responses, and metabolic disorders due to oxidative stress.

\section{Acknowledgements}

This study is not produced from a doctoral-PhD or master's thesis or presented at scientific meetings.

\section{Financial Support}

This study was supported by Ankara University Scientific Research Grant (Grant No: 20B0239002).

\section{Conflict of Interest}

The authors declared that there is no conflict of interest.

\section{Author Contributions}

EK, AK, NÖ and EK conceived and planned the experiments. EK, AK, NÖ and EK carried out the experiments. EK, AK, NÖ and EK planned and carried out the simulations. EK, AK, NÖ and EK contributed to sample preparation. EK, AK, NÖ and EK contributed to the interpretation of the results. EK, AK, NÖ and EK took the lead in writing the manuscript. All authors provided critical feedback and helped shape the research, analysis and manuscript.

\section{Data Availabiliity Statement}

The data supporting this study's findings are available from the corresponding author upon reasonable request.

\section{Ethical Statement}

This study was approved by the Kırıkkale University Animal Experiments Local Ethics Committee (Decision No: 2019/10/48).

\section{Animal Welfare}

The authors confirm that they have adhered to ARRIVE Guidelines to protect animals used for scientific purposes.

\section{References}

1. Agalakova NI, Gusev GP (2012): Molecular mechanisms of cytotoxicity and apoptosis induced by inorganic fluoride. ISRN Cell Biol, Article ID 403835.

2. Antanaitis R, Juozaitiene V, Malasauskiene D, et al (2019): Can rumination time and some blood biochemical parameters be used as biomarkers for the diagnosis of subclinical acidosis and subclinical ketosis. Vet Anim Sci, 8, 100077.

3. Badman MK, Pissios P, Kennedy AR, et al (2007): Hepatic fibroblast growth factor 21 is regulated by PPAR alpha and is a key mediator of hepatic lipid metabolism in ketotic states. Cell Metab, 5, 426-437.

4. Basbug O, Akar Y, Ercan N (2014): The investigation of the prevalence of subclinical ketosis in Sivas region dairy cows. Eurasian J Vet Sci, 30, 123-128.

5. Bernabucci U, Ronchi B, Lacetera N, et al (2005): Influence of body condition score on relationships between metabolic status and oxidative stress in periparturient dairy cows. J Dairy Sci, 88, 2017-2026.

6. Bruckmaier RM, Gross JJ (2017): Lactational challenges in transition dairy cows. Anim Prod Sci, 57, 1471-1481.

7. Brunner N, Groeger S, Raposo JC, et al (2018): Prevalence of subclinical ketosis and production diseases in dairy cows in Central and South America, Africa, Asia, Australia, New Zealand, and Eastern Europe. Transl Anim Sci, 3, 84-92.

8. Chen Y, Dong Z, Li R, et al (2018): Changes in selected biochemical parameters (including FGF21) during 
subclinical and clinical ketosis in dairy cows. Med Weteryn, 74, 727-730.

9. Fiore E, Piccione G, Rizzo M, et al (2018): Adaptation of some energetic parameters during transition period in dairy cows, J Appl Anim Res, 46, 402-405.

10. Folnozic I, Turk R, Duricic D, et al (2015): Influence of Body Condition on Serum Metabolic Indicators of Lipid Mobilization and Oxidative Stress in Dairy Cows During the Transition Period. Rep Domestic Anim, 50, 910-917.

11. Gavan C, Retea C, Motorga V (2010): Changes in the hematological profile of Holstein primiparous in periparturient period and in early to mid-lactation. Anim Sci Biotec, 43, 244-246.

12. Grummer RR (1993): Etiology of lipid-related metabolic disorders in periparturient dairy cows. J Dairy Sci, 76, 3882-3896.

13. Halliwell B (2007): Biochemistry of oxidative stress. Biochem Soci Trans, 35, 1147-1150.

14. Ingvartsen KL (2006): Feeding-and management-related diseases in the transition cow: Physiological adaptations around calving and strategies to reduce feeding-related diseases. Anim Feed Sci, Technol, 126, 175-213.

15. Issi M, Gül Y, Basbug O (2016): Evaluation of renal and hepatic functions in cattle with subclinical and clinical ketosis. Turk J Vet Anim Sci, 40, 47-52.

16. Karimi N, Mohri M, Azizzadeh M, et al (2015): Relationships between trace elements, oxidative stress and subclinical ketosis during transition period in dairy cows. Iran J Vet Sci Techn, 7, 46-56.

17. Lacetera N, Scalia D, Franci O, et al (2004): Short communication: effects of nonesterified fatty acids on lymphocyte function in dairy heifers. J Dairy Sci, 87, 10121014.

18. Li XB, Zhang ZG, Liu GW, et al (2011): Renal function of dairy cows with subclinical ketosis. Vet Rec, 168, 643.

19. Loor JJ, Everts RE, Bionaz M, et al (2007): Nutritioninduced ketosis alters metabolic and signaling gene networks in liver of periparturient dairy cows. Physiol Genomics, 32, 105-116.

20. Mamedova LK, Robbins K, Johnson BJ, et al (2010): Tissue expression of angiopoietin-like protein 4 in cattle. $\mathrm{J}$ Anim Sci, 88, 124-130.

21. Marutsova V, Binev R, Marutsov P (2015): Comparative clinical and haematological investigations in lactating cows with subclinical and cliniical ketosis. Mac Vet Rev, 38, 159166.

22. Marutsova VJ, Marutsov PD, Binev RG (2019): Evaluation of some blood liver parameters in cows with subclinical and clinical ketosis. Bulgarian J Vet Med, 22, 314-321.

23. Mazur A, Rayssiquier Y (1988): Lipoprotein profile of the lactating cow. Ann Rech Vet, 19, 53-58.

24. Opsomer G (2015): Interaction between metabolic challenges and productivity in high yielding dairy cows. Jap J Vet Res, 63, 1-14.

25. Rodriguez-Jimenez S, Haerr KJ, Trevisi E, et al (2018): Prepartal standing behavior as a parameter for early detection of postpartal subclinical ketosis associated with inflammation and liver function biomarkers in peripartal dairy cows. Journal of Dairy Science, 101, 8224-8235.
26. Sahoo SS, Patra RC, Behera PC, et al (2009): Oxidative stress indices in the erythrocytes from lactating cows after treatment for subclinical ketosis with antioxidant incorporated in the therapeutic regime. Vet Res Commun, 33, 281-290.

27. Sato S, Kohno M, Ono H (2005): Relation between blood $\beta$-hydroxybutyric acid and glucose, non-esterified fatty acid and aspartate aminotransferase in dairy cows with subclinical ketosis. Jap J Vet Clin, 28, 7-13.

28. Schlegel G, Ringseis R, Keller J, et al (2013): Expression of fibroblast growth factor 21 in the liver of dairy cows in the transition period and during lactation. $\mathrm{J}$ Anim Physiol Anim Nutr, 97, 820-829.

29. Schoenberg KM, Giesy SL, Harvatine KJ, et al (2011): Plasma FGF21 is elevated by the intense lipid mobilization of lactation. Endocrinol, 152, 4652-4661.

30. Schulz K, Frahm J, Kersten S, et al (2014): Effects of elevated parameters of subclinical ketosis on the immune system of dairy cows: in vivo and in vitro results. Arch Anim Nutr, 69, 113-127.

31. Senoh T, Oikawa S, Nakada K, et al (2019): Increased serum malondialdehyde concentration in cows with subclinical ketosis. J Vet Med Sci, 81, 817-820.

32. Sun Y, Wang B, Shu S, et al (2015): Critical thresholds of liver function parameters for ketosis prediction in dairy cows using receiver operating characteristic (ROC) analysis. Vet Quarterly, 35, 159-164.

33. Trevisi E, Amadori M, Cogrossi S, et al (2012): Metabolic stress and inflammatory response in high-yielding, periparturient dairy cows. Res Vet Sci, 93, 695-704.

34. Trevisi E, Jahan N, Bertoni G, et al (2015): ProInflammatory Cytokine Profile in Dairy Cows: Consequences for New Lactation. Italian J Anim Sci, 14, 3862.

35. Turk R, PodpeCan O, Mrkun J, et al (2013): Lipid mobilisation and oxidative stress as metabolic adaptation processes in dairy heifers during transition period. Anim Repr Sci, 141, 109-115.

36. Wang J, Zhu X, She G, et al (2018): Serum hepatokines in dairy cows: periparturient variation and changes in energyrelated metabolic disorders. BMC Veterinary Research, 14, 236.

37. Wankhade PR, Manimaran A, Kumaresan A, et al (2017): Metabolic and immunological changes in transition dairy cows: A review. Vet World, 10, 1367-1377.

38. Yang W, Zhang B, Xu C, et al (2019): Effects of ketosis in dairy cows on blood biochemical parameters, milk yield and composition, and digestive capacity. J Vet Res, 63, 555-560.

39. Zhang Y, Li X, Zhang H, et al (2018): Non-Esterified Fatty Acids Over-Activate the TLR2/4-NF-Kb Signaling Pathway to Increase Inflammatory Cytokine Synthesis in Neutrophils from Ketotic Cows. Cell Physiol Biochem, 48, 827-837.

\section{Publisher's Note}

All claims expressed in this article are solely those of the authors and do not necessarily represent those of their affiliated organizations, or those of the publisher, the editors and the reviewers. Any product that may be evaluated in this article, or claim that may be made by its manufacturer, is not guaranteed or endorsed by the publisher. 